\title{
Factors Affecting the Acceptance of Online Learning among the Urban Poor: A Case Study of Malaysia
}

\author{
Nornadia Azhar ${ }^{1, *}$, Wan Fatimah Wan Ahmad ${ }^{1} \oplus$, Rohiza Ahmad ${ }^{1}$ and Zainab Abu Bakar ${ }^{2}$ \\ 1 Computer and Information Sciences Department, Universiti Teknologi PETRONAS, \\ Seri Iskandar 32610, Malaysia; fatimhd@utp.edu.my (W.F.W.A.); rohiza_ahmad@utp.edu.my (R.A.) \\ 2 Faculty of Computer and Information Technology, Al-Madinah International University, \\ Kuala Lumpur 57100, Malaysia; zainab.abubakar@mediu.edu.my \\ * Correspondence: nornadia_19001076@utp.edu.my
}

check for updates

Citation: Azhar, N.; Wan Ahmad, W.F.; Ahmad, R.; Abu Bakar, Z. Factors Affecting the Acceptance of Online Learning among the Urban Poor: A Case Study of Malaysia. Sustainability 2021, 13, 10359. https://doi.org/10.3390/ su131810359

Academic Editors: Hong-Ren Chen, Wen-Shan Lin and Hao-Chiang Koong Lin

Received: 25 July 2021

Accepted: 12 September 2021

Published: 16 September 2021

Publisher's Note: MDPI stays neutral with regard to jurisdictional claims in published maps and institutional affiliations.

Copyright: (c) 2021 by the authors. Licensee MDPI, Basel, Switzerland. This article is an open access article distributed under the terms and conditions of the Creative Commons Attribution (CC BY) license (https:// creativecommons.org/licenses/by/ $4.0 /)$.

\begin{abstract}
Education is an avenue of gaining knowledge and skills that will, in turn, support economic growth. Therefore, as online learning platforms are abundantly available in Malaysia, the urban poor in the Klang Valley have a means of improving their knowledge and skills to generate more income. However, online learning requires technical readiness. As such, this study examined the factors affecting the acceptance of online learning among the urban poor in Malaysia. An acceptance model was developed by integrating the constructs of the unified theory of acceptance and use of technology (UTAUT) with factors that influence the perceived value of online learning among the urban poor. To assess the reliability of these factors, 293 respondents participated in an online survey. SmartPLS 3.0 was then used to analyse the collected data. We found that performance expectancy (PE), facilitating conditions (FC), and perceived value (PV) positively influenced the behavioural intention to use (BI) online learning. Therefore, the findings of this study provide an understanding of the value and vital factors that impact the acceptance of online learning among the urban poor in the Klang Valley.
\end{abstract}

Keywords: acceptance model; factors; online education; urban poor; UTAUT model

\section{Introduction}

Information communication technology (ICT) pervades every aspect of our lives, be it for personal use or for business purposes. For instance, ICT enables organisations to gather and store large amounts of data that could be used for further analysis, the results of which would be helpful in modelling, projecting, and predicting market trends and others [1]. Furthermore, ICT can improve many aspects of life, including that of individuals. Therefore, this study investigated how ICT could improve the standard of living of a community.

In Malaysia, the urban poor or B40 community is classified as persons living in the Klang Valley, the area surrounding the capital city of Kuala Lumpur, with monthly household incomes below RM 4850 (approximately USD 1145 or EUR 975) [2]. This community is presently struggling to survive due to limited income and the high cost of living in the city. Therefore, the Malaysian government has made improving the welfare and quality of life of the B40 community a priority of the Eleventh Malaysia Plan (11MP) in the hopes of narrowing the socioeconomic gap of its citizens [3]. One of the initiatives of the 11MP is the introduction of several income generation supports, such as business-related projects and schemes [1]. The Digital Malaysia (DM) programme, which was introduced in 2012, is another initiative that aims to provide digital access to all communities and, therefore, could serve as a platform for business opportunities among the B40 community [3]. In 2015, the Malaysia Digital Economy Corporation (MDEC) launched the eRezeki digital platform (https: / / mdec.my / erezeki / accessed 23 June 2021) specifically for the B40 community to generate more income via a digital economy and improve their living conditions. Inspired 
by crowdsourcing, the platform enables users to earn an additional income by performing digital tasks anytime anywhere.

However, there is no guarantee that the target community, the B40 in this case, will be willing to take advantage of the abovementioned opportunities. Hamid et al. [4] investigated the involvement of urban poor entrepreneurs in e-commerce and found a lack of participation in the advertising and trading industries. This is partly because technology preparedness is a fundamental element of online service-related jobs. Therefore, participants were provided with training that emphasised methods of completing sufficient assignments and becoming a dynamic digital personnel [4].

Professionals and participants commonly rely on online learning and training programmes such as web-based programmes, e-learning, m-learning, and massive open online courses (MOOCs) to impart as well as receive knowledge and skills. As such, many academic institutions have earmarked a considerable amount of capital to provide online learning programmes that incorporate various learning methods and to reinforce ties between formal and informal platforms, including the formal validation of training and education experiences, skills, and qualifications [5]. Virtual and online learning platforms provide students with new alternatives with which to access tertiary education. They also narrow the disparity in education for underprivileged populations. As this type of learning transforms how people access digital content, it creates new prospects for learning and the development of skills. Furthermore, entrepreneurship-related programmes are in high demand at the moment [5]. This is because the objectives of such programmes often include increasing self-employment opportunities. In addition to existing online learning platforms, the Industrial Revolution (IR) 4.0 has impacted Malaysia as much as it has impacted the rest of the world. Considering this, most educational institutions advocate Education 4.0 and adopting the latest technology innovations for education transformation.

Authorities still find it difficult to determine the extent of participation in the abovementioned opportunities and initiatives by the urban poor. The Department of Statistics Malaysia (DoSM) [6] reports that the urban poor generally cannot afford better education due to the exorbitant cost of education, which includes training charges, extra tuition charges, and other course-related fees. Therefore, this study will illuminate the factors affecting the acceptance of online learning in this community. The unified theory of acceptance and use of technology (UTAUT) model was integrated with an extra factor, i.e., perceived value $(\mathrm{PV})$, to assess the behavioural intention of the urban poor. Chen and Hwang [7] state that not many studies have utilised the UTAUT model to investigate online learning among the urban poor. Therefore, this study will help identify and explain the factors that influence the acceptance of online learning platforms among the urban poor. The degree of acceptance influences the efficacy of online learning platforms in enhancing the lives of the urban poor.

\section{Literature Review}

\subsection{The Urban Poor}

The 2020 Salaries \& Wages Survey Report of the DoSM [8] reported that the average monthly income of the urban poor dropped by $9.3 \%$ in one year, that is, from RM 3405 (USD 803.45) in 2019 to RM 3089 (USD 728.88) in 2020. Meanwhile, low-income earners and low-income households (B40 group) earned less than RM 4850 (USD 1145) per month [6]. Currently, over 1.6 million Malaysians belong to the B40 group. This group is unable to support the high cost of living, particularly in cities, because they lack sufficient income to support their needs. As such, several concerns have been raised; including difficulties faced by single parents, a lack of capacities and expertise, and health issues [2]. Many of the urban poor face destitution as their income is not commensurable with the rising cost of living. Furthermore, they need to strive for a better life while contending with the middle $40 \%$ (M40 group) and upper 20\% (T20 group), particularly in urban cities.

The range of characteristics of the urban poor include less income, limited access to essential public amenities and social services, adequate accommodation, and fewer 
employment opportunities. The state of Selangor has the highest concentration (16.6\%) of B40s while the city of Putrajaya has the fewest (0.1\%) [2]. Sadly, the number of urban poor continues to rise despite Malaysia's rapid urbanisation. This fact is evidenced by an increase in the number of zakat (Islamic almsgiving) recipients [2]. Therefore, considering the numerous factors that increase the number of urban poor, the authorities need to prioritise finding a solution to eradicate these factors. Furthermore, extensive research is required to fully comprehend the current predicaments of the urban poor.

\subsection{Online Learning}

The development of advanced technologies in the education industry has had a significant impact over the years [9]. For instance, education methods have slowly shifted to new technology-oriented lessons with further transformations anticipated soon. Online learning not only attests to the adaptability of learning in terms of time and location but also reaffirms the self-management of learners during the learning process as well [7]. However, the effective application of online learning hinges on the recognition and the level of confidence in the latest technologies.

E-learning is a cutting-edge online system designed to improve the efficacy of teaching and learning via the use of digital resources and communication [10]. Virtual seminar learning, digital teamwork learning, and network-oriented learning are just some of the many forms of e-learning [11]. E-learning not only empowers technology and internet revolutions to transfer data, information, aptitudes, and education but provides educators and learners with a plethora of opportunities as well [12]. Furthermore, it also enables students to explore and comprehend the use of broadcasting and mass media revolution to set up virtual courses as well as acquire better material with which to produce facts and reports on their own. The rapid progression of smartphones and wireless technologies has led to an increase in the usage of smartphones and other devices in education as well as upgraded the methods of teaching and learning [13].

Over the passage of time, education-based technology has evolved from encoded commands within a computer-supported command to network-linked online learning (e-learning) and, finally, to mobile learning (m-learning). M-learning is an important component of tertiary education as it allows students to access knowledge at any time and from any location. Furthermore, students can access this information and resources via their mobile devices, which allows them to participate in real-world exercises [13]. Therefore, learners can easily access various knowledge-based resources through smart devices, such as smartphones and tablets. As m-learning is quickly becoming an essential element of education, its acceptance and recognition has garnered the attention of experts, educators, and learners alike [13].

Education is a crucial in equipping the urban poor with the expertise needed to improve their standards of living [14]. As part of its many strategies of introducing virtual and online learning in the country, in 2016, the Malaysian government launched adaptable education programmes, such as Massive Open Online Courses (MOOCs), to produce more comprehensive learners. Other examples of government initiatives include the $2 \mathrm{u} 2 \mathrm{i}$ programme as well as the Accreditation of Prior Experiential Learning (APEL) process [9]. More recently, the e-LATiH free online training portal (https: / / elatih.hrdcorp.gov.my / accessed 18 July 2021) was introduced. Financed by the Human Resources Development Corporation (HRD Corp., Kuala Lumpur, Malaysia), the portal provides Malaysians with more than hundreds of open online courses in various fields with which to advance their expertise. As such, this study intended to extensively investigate the acceptance of online learning among the urban poor in Malaysia.

\subsection{The UTAUT Model}

The acceptance and recognition of new technological innovations by users is one of the main areas of study in the field of information systems [15]. Venkatesh et al. [16] formulated the unified theory of acceptance and use of technology (UTAUT) model by combining 
multiple other models and theories. The primary purpose of the UTAUT model is to assess the acceptance and usage of information technology (IT) in an organisational setting as well as the possibility of utilising new IT innovations [7].The four key constructs of the UTAUT model are performance expectancy (PE), effort expectancy (EE), social influence (SI), facilitating conditions (FC), behavioural intention to use (BI), and usage behaviour as well as four moderators (age, gender, experience, and voluntariness). [7] The UTAUT model describes the methods in which users accept new IT innovations by expanding the technology acceptance model (TAM). The UTAUT model is also able to account for $70 \%$ of the variance in user acceptance. It correlates both individual and social attitudes to comprehensively demonstrate the behaviour intention of users to accept and adopt new technological innovations [1]. This study intended to examine the acceptance of online learning platforms through behavioural intention to use (BI). As such, the usage behaviour construct of the UTAUT model was not included in the proposed model [7].

The purpose of the four moderators of the UTAUT model is to evaluate reactions from extremely different communities. However [7], it is noteworthy that the moderators did not have a moderating influence on online learning platforms in institutions. As such, these four moderators were excluded in this study. Since its inception, the ability of the UTAUT model to forecast the acceptance of new technologies such as smart virtual whiteboard, mobile health technology (mHealth), and enterprise resource planning (ERP) systems has been comprehensively tested [13]. Factors such self-ability, perceived trust, and satisfaction have been suggested for integration into the original UTAUT model [13]. For instance, [17] integrated subjective innovation to IT and trust in the UTAUT model to analyse the factors that affect the behavioural intentions of users to employ IT. Perceived value (PV) is a criterion for evaluating entire systems or services on an individual basis, taking into consideration the exertions taken in reference to the standards of benefits and advantages achieved [18]. When it comes to the perception of value, there are objective and subjective elements that all work together to create the user's perception of the value of the product or service [19]. PV, according to findings by [18], has a significant role in the acceptability of online learning platforms, both explicitly and implicitly. In the advertising and information systems (IS) areas, PV is critical when attempting to comprehend user behavior, for instance, technology acceptance and implementation [20]. As a key determinant of user behavioral intention, perceived value refers to a systems' total perceived value assessment by the prospective users. Hence, this study plans to include the perceived value (PV) construct in the proposed acceptance model in order to discover the value of online learning platforms as perceived by prospective users.

\subsection{Literature Review on UTAUT Model}

To identify the factors influencing the acceptance of online learning platforms among the urban poor in Malaysia, a literature review was conducted and yielded eight related articles from various databases. Existing studies indicate that the variables of behavioural intention most utilised in the UTAUT model were performance expectancy (PE), effort expectancy (EE), social influence (SI), facilitating condition (FC), and behavioural intention to use (BI) (Table 1). Therefore, these four factors (PE, EE, SI, and FC) were the independent variables used in this study to classify the factors that influence the acceptance of online learning platforms among the urban poor.

PE, EE, SI, and FC were the most-tested UTAUT factors with PE supported in all the studies in listed in Table 1. Therefore, PE was evidently the most influential factor. However, several studies added extra factors in their research models of technological acceptance or adoption. Among the factors added were convenience of online access (CON), innovativeness in IT (INN), empowerment, and the SERVQUAL dimensions (reliability, responsiveness, assurance, empathy, and tangibles) (Table 1). 
Table 1. Comparative summary of UTAUT model.

\begin{tabular}{|c|c|c|c|}
\hline Model & Author & Purpose & Factors Tested \\
\hline UTAUT & Mandailina et al. [21] & $\begin{array}{l}\text { To investigate how instructors and } \\
\text { students in Indonesian } \\
\text { educational institutions are using } \\
\text { Android applications as a channel } \\
\text { for studying mathematics. }\end{array}$ & $\begin{array}{l}\text { Supported-PE, EE, } \\
\text { SI, FC, BI }\end{array}$ \\
\hline UTAUT & Chauhan \& Jaiswal [22] & $\begin{array}{l}\text { To find out what factors influence } \\
\text { students' acceptability of ERP } \\
\text { software learning in business } \\
\text { schools in India. }\end{array}$ & $\begin{array}{l}\text { Supported-PE, EE, } \\
\text { FC, BI, CON, INN } \\
\text { Not supported-SI }\end{array}$ \\
\hline UTAUT \& SERVQUAL & Park \& Lee [23] & $\begin{array}{l}\text { Understanding the variables } \\
\text { influencing users' willingness to } \\
\text { accept the online education service } \\
\text { in the early stages of revival and } \\
\text { investigating the consequences of } \\
\text { these factors on their willingness } \\
\text { to embrace the service. }\end{array}$ & $\begin{array}{l}\text { Supported-PE, SI, } \\
\text { Tangible, and } \\
\text { empathy. } \\
\text { Not Supported-EE, } \\
\text { Reliability, } \\
\text { Responsiveness, } \\
\text { Assurance }\end{array}$ \\
\hline UTAUT & Naranjo-Zolotov et al. [24] & $\begin{array}{c}\text { To find out how people' } \\
\text { perceptions of empowerment } \\
\text { impact their willingness to utilize } \\
\text { and advocate e-participation in } \\
\text { Portugal. }\end{array}$ & $\begin{array}{l}\text { Supported-PE, FC, } \\
\text { BI, Empowerment. } \\
\text { Not Supported-EE, } \\
\text { SI }\end{array}$ \\
\hline UTAUT & Abbad [25] & $\begin{array}{l}\text { To examine students' willingness } \\
\text { to utilize and actual use of Moodle, } \\
\text { an e-learning platform, at } \\
\text { Hashemite University in Jordan. }\end{array}$ & $\begin{array}{c}\text { Supported-PE, EE, } \\
\text { FC, BI } \\
\text { Not Supported-SI }\end{array}$ \\
\hline UTAUT & Persada et al. [26] & $\begin{array}{l}\text { To develop a greater } \\
\text { understanding of Generation Z's } \\
\text { attitudes towards digital learning } \\
\text { in Indonesia. }\end{array}$ & $\begin{array}{l}\text { Supported-PE, EE, } \\
\text { SI, FC }\end{array}$ \\
\hline UTAUT & Padhi [27] & $\begin{array}{l}\text { To explore at the acceptability and } \\
\text { usage of open educational } \\
\text { resources (OER) in India. }\end{array}$ & $\begin{array}{l}\text { Supported-PE, EE } \\
\text { Not Supported-SI, } \\
\text { FC }\end{array}$ \\
\hline UTAUT & Hamdan et al. [28] & $\begin{array}{l}\text { To assess the factors that influence } \\
\text { how Malaysian workers utilize } \\
\text { MOOCs for management training } \\
\text { and how they intend to use them } \\
\text { in the future. }\end{array}$ & $\begin{array}{c}\text { Supported-PE, SI, } \\
\text { FC } \\
\text { Not Supported-EE }\end{array}$ \\
\hline
\end{tabular}

$\overline{\mathrm{PE}}=$ Performance Expectancy; EE = Effort Expectancy; $\mathrm{SI}$ = Social Influence; FC = Facilitating Conditions; $\mathrm{BI}=$ Behavioral Intention; $\mathrm{CON}=$ Convenience from Online Access; INN = Innovativeness in IT.

\section{Methodology}

This study incorporated the UTAUT model with a perceived value factor in the acceptance model (Figure 1). All the constructs on the UTAUT model were used in this analysis except for usage behaviour. The perceived value factor was proposed as a part of value in terms of effort and time consumed as well as the benefit of utilising online learning platforms.

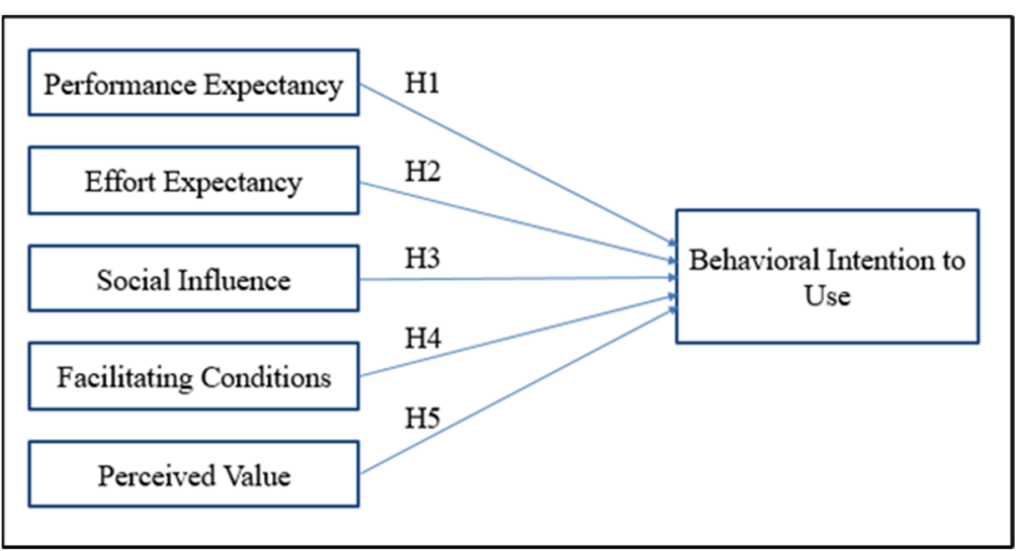

Figure 1. The proposed acceptance model. 


\subsection{Hypothesis Development}

Of the five hypotheses proposed in this study, four were derived from the UTAUT constructs of performance expectancy (PE), effort expectancy (EE), social influence (SI), and facilitating conditions (FC), while the fifth hypothesis, perceived value (PV), was included as a factor that could possibly impact the behavioural intention of accepting online learning amongst the urban poor in the Klang Valley area of Malaysia. As this study utilised the cross-sectional method proposed by [29], the scope of the study was limited to evaluating the acceptance of and intention towards technology instead of the actual usage behaviour on online learning platforms. Therefore, only the behavioural intention to use (BI) of the UTAUT model was studied while the usage behaviour was excluded. The factor-based hypotheses of this study are described in the following paragraphs.

Performance expectancy (PE) refers to "the level to which a person trusts that by utilising the system, it will support him or her to achieve good improvements in career performance" [16-29]. Therefore, our hypothesis for PE is as follows:

Hypothesis 1 (H1): Performance expectancy (PE) has a positive influence on the behavioural intention to use (BI) any online learning platforms.

Effort expectancy (EE) refers to "the level of ease related with the usage of the system" [16]. Therefore, our hypothesis for EE is as follows:

Hypothesis 2 (H2): Effort expectancy (EE) has a positive influence on the behavioural intention to use (BI) any online learning platforms.

Social influence (SI) refers to "the level to which a person perceives the importance of others' belief of using the new system" [16]. In the current perspective, SI is the level of importance that a person confers on the opinion of others on whether he or she should utilise the recommended online learning platform(s). Therefore, our hypothesis for SI is as follows:

Hypothesis 3 (H3): Social influence (SI) has a positive influence on the behavioural intention to use (BI) any online learning platforms.

Facilitating conditions (FC) refer to "the level to which a person trusts that organisational and technological infrastructure exists as an assistance to the usage of the system" [16]. In this context of this study, FC is defined as the extent to which a person trusts that organisational and technological infrastructure exists to facilitate the use of any online learning platforms. Therefore, our hypothesis for FC is as follows:

Hypothesis 4 (H4): Facilitating conditions $(F C)$ have a positive influence on the behavioural intention to use (BI) any online learning platforms.

Lastly, the additional construct of perceived value (PV) refers to "an overall evaluation by a person of the usefulness of a system based on insight of what has been obtained and offered" [30]. Comprehending the values perceived by prospective users is vital, and a user's judgment of a specific system's qualities may give a base for defining and improving the value of the system. Intentions also are influenced by perceived value, which represents utility through the comparison of relevant advantages and sacrifices $[28,30]$. When it comes to the domain of ICT or new systems, which includes e-Learning [26,29], wearable gadgets and tablets [27,28], mobile banking [31], and carpooling services [32], perceived value has been found to be a potent predictor of behavioral intentions. Moreover, "the perceptions of values or expenses may be monetary or non-monetary" [33]. However, the expense to learners is not principally monetary as almost all the online learning platforms available are free and open to all. As such, the expense to learners alludes to the time and effort that must be dedicated to using these online learning platforms. Furthermore, [34] found 
that PV influences the behavioural intention to use (BI) mobile devices. Therefore, our hypothesis for PV is as follows:

Hypothesis 5 (H5) : Perceived value (PV) has a positive influence on the behavioural intention to use (BI) any online learning platforms.

\subsection{Instrument}

This study adopted a quantitative approach in the form of a survey. The questionnaires were constructed to measure the awareness as well as determine the factors influencing the acceptance and the behavioural intention to use (BI) of online learning platforms among the urban poor of the Klang Valley area of Malaysia. An online survey was conducted to evaluate the reliability of the factors in the model. The online survey consisted of seven segments. Except for the first segment, which collected the demographic data of the respondents, all the other segments contained questions relating to the model presented in Figure 1. Each question was also closed-ended. As proposed by [35], respondents were required to choose between a range of answers listed in a Likert scale format of 1 to 5 . The target respondents were from the B40 group only, i.e., the urban poor from the Klang Valley. The online survey was developed by adapting the items and questionnaires of Sabah [36] and Mulik, Srivastava, and Yajnik [29].

The purpose of the first segment was to obtain and verify the demographic data of the respondents. This included gender, age, highest education level, income range, location, and awareness of any online learning platforms. The second to seventh segments focused on the essential investigations of this study, i.e., performance expectancy (PE), effort expectancy (EE), social influence (SI), facilitating conditions (FC), perceived value $(\mathrm{PV})$, and behavioural intention to use (BI), respectively. The purpose of the last segment was to determine how likely the respondents were to utilise any online learning platforms in the future. The answers selected by the respondents were evaluated using the following 5-point Likert scale: 1-strongly disagree, 2-disagree, 3-neutral/not sure, 4-agree, and 5-strongly agree. The structured online questionnaire consisted of a total of 27 questions and was circulated to respondents via social media platforms such as Gmail, WhatsApp, Facebook, Twitter, and Instagram. It was also bilingual as it was available in both Malay and English. SmartPLS 3.0 software was then used to analyse the information provided by the respondents. A sample size of 307 was determined using the Cochran formula [37,38]. However, as the survey was conducted online, a total of 312 responses were obtained, but only 293 responses met all the requirements.

\subsection{Analysis Tools}

Structural equation modelling (SEM) is a great statistical technique capable of both testing a sequence of distinct multiple regression calculations [7] and assessing the acceptability and validity of a proposed acceptance model. SmartPLS 3.0 is a software that evaluates and decodes the reliability and validity of a structural model by bootstrapping the proposed acceptance model to reveal correlations between the hypothesised factors as well as confirm or deny support [13]. Outer model exploration, inner model exploration, and hypothesis confirmation are among the phases executed [15]. As such, the statistical methods below were used to analyse the data.

1. Descriptive analysis: to measure the frequency and percentage data of the respondents' demographic profiles.

2. Outer model analysis: Outer model exploration checks the validity and reliability of a factor in the proposed acceptance model [39]. The validity of the acceptance model was evaluated using convergent validity. Convergent validity elucidates the extent to which manifold items compute to a single construct or factor. The convergent validity of a construct or factor can be quantified by calculating its Cronbach's alpha (CA) and average variance extracted (AVE) [39]. Next, internal consistency reliability was utilised to determine the reliability of each construct and determine the internal 
consistency of each survey item [35] by calculating the composite reliability (CR) and Cronbach's alpha (CA) [7]. A CR and CA of $\geq 0.7$ is required to prove that a construct has good reliability $[15,39]$. Furthermore, if the factor loading of an item or questionnaire exceeds 0.7 , it can be deemed reliable. However, other scholars acknowledge a construct's reliability so long as it exceeds 0.6 [35]. Discriminant validity determines if the items or questionnaires of each construct is completely different from the items or questionnaires of the other constructs in the model. Henseler, Ringle, and Sarstedt (2015) [40] developed the heterotrait-monotrait ratio of correlations (HTMT), a new technique of testing and proving discriminant validity. The HTMT is the average value of an item's correlation to a factor in comparison to the mean of the average correlations for items assessing a similar factor. Henseler et al. [40] advise a lower verge value of 0.85 or 0.90 for HTMT.

3. Structural model analysis: To measure the path coefficients $(\beta)$, the variance inflation factor (VIF) to detect multicollinearity, and the hypothesis confirmation outcome, the bootstrapping method was used to analyse and check the results of the hypotheses that focused on the correlation between PE, EE, SI, FC, and PV on BI.

\section{Results}

\subsection{Descriptive Analysis}

Of the 293 respondents, $117(40 \%)$ were male and $176(60 \%)$ were female. The respondents ranged from 18 to 54 years old. Table 2 depicts the demographic profile of the 293 respondents who completed the survey properly. A total of 159 respondents (54\%) were between 25 to 34 years old while 123 (42\%) were between 18 to 24 years old. Only 11 respondents (4\%) were $\geq$ the age of 35 . In terms of highest education level, 226 respondents $(77 \%)$ had a bachelor's degree while the others had diplomas $(11 \%)$, master's degrees $(8 \%)$, Malaysian Certificates of Education or SPM $(2 \%)$, or doctoral certificates or doctorate degrees (1\%). Regarding income, 144 respondents $(49 \% \%)$ had salaries between RM 2000 to RM 2999 while the others had salaries ranging between RM 3000 to RM 3999 (33\%), RM 1000 to RM 1999 (15\%), or $\leq$ RM 1000 (3\%). A total of 263 respondents (90\%) were aware of the online learning platforms available while 30 respondents $(10 \%)$ were not. However, although $90 \%$ of the respondents were aware of the online learning platforms, 195 of them $(67 \%)$ were not enrolled in any online learning platforms at the time of the writing. This proved that awareness of online learning platforms among the urban poor was excellent; however, usage remained low.

\subsection{Convergent Validity}

To prove good convergent validity, the CA must be $\geq 0.7$ while the AVE of each constructs must be $\geq 0.5[15,35,39]$. An AVE of $\leq 0.5$ indicates the presence of lingering mistakes in the items than the variance described. As seen in Table 3, the AVE of the constructs were all $\geq 0.5$, ranging between 0.615 to 0.819 . As the $C A$ and $C R$ of the constructs surpassed the recommended thresholds of 0.6 and 0.7 , respectively, the constructs had great internal reliability. The results of the reliability and convergent validity assessment are presented in Table 3. 
Table 2. Demographic profiles.

\begin{tabular}{cccc}
\hline Demographic & Category & Frequency & Percentage (\%) \\
\hline \multirow{2}{*}{ Gender } & Male & 117 & 40 \\
& Female & 176 & 60 \\
\hline \multirow{3}{*}{ Age Group } & $18-24$ & 123 & 42 \\
& $25-34$ & 159 & 54 \\
& $35-44$ & 3 & 2 \\
& $45-54$ & 3 & 1 \\
\hline \multirow{2}{*}{ Status } & $55-64$ & 229 & 78 \\
& Single & 64 & 22 \\
\hline & Married & 7 & 2 \\
Education Level & SPM or other equivalent & 2 & 1 \\
& level & 32 & 11 \\
& Certificate & 226 & 8 \\
& Diploma & 24 & 1 \\
\hline & Bachelor's Degree & 2 & 3 \\
& Master's Degree & 8 & 49 \\
& Doctorate Degree (PhD) & 44 & 33 \\
\hline Income Group & <M 1000 & 144 & 90 \\
& RM 1000-RM 1999 & 97 & 10 \\
\hline RM 2000-RM 2999 & 263 & 79 \\
Awareness of the existence of online & RM 3000-RM 3999 & 30 & 21 \\
\hline Experience of using any online & Yes & 232 & 33 \\
education program platforms & No & 61 & 67 \\
\hline Enrolled in any online education & Yes & 98 & \\
program platforms & No & 195 & \\
\hline
\end{tabular}

Table 3. Reliability and convergent validity assessment.

\begin{tabular}{|c|c|c|c|c|c|}
\hline Constructs/Factors & Items & Loadings & CA & CR & AVE \\
\hline \multirow{4}{*}{ Behavioral Intention (BI) } & BI1 & 0.929 & \multirow{4}{*}{0.906} & \multirow{4}{*}{0.934} & \multirow{4}{*}{0.781} \\
\hline & BI2 & 0.910 & & & \\
\hline & BI3 & 0.804 & & & \\
\hline & BI4 & 0.887 & & & \\
\hline \multirow{5}{*}{$\begin{array}{l}\text { Performance Expectancy } \\
\text { (PE) }\end{array}$} & PE1 & 0.812 & \multirow{5}{*}{0.903} & \multirow{5}{*}{0.928} & \multirow{5}{*}{0.721} \\
\hline & PE2 & 0.857 & & & \\
\hline & PE3 & 0.891 & & & \\
\hline & PE4 & 0.855 & & & \\
\hline & PE5 & 0.829 & & & \\
\hline \multirow{5}{*}{ Effort Expectancy (EE) } & EE1 & 0.783 & \multirow{5}{*}{0.844} & \multirow{5}{*}{0.889} & \multirow{5}{*}{0.615} \\
\hline & EE2 & 0.792 & & & \\
\hline & EE3 & 0.792 & & & \\
\hline & EE4 & 0.778 & & & \\
\hline & EE5 & 0.776 & & & \\
\hline \multirow{5}{*}{ Social Influence (SI) } & SI1 & 0.883 & \multirow{5}{*}{0.921} & \multirow{5}{*}{0.941} & \multirow{5}{*}{0.761} \\
\hline & SI2 & 0.908 & & & \\
\hline & SI3 & 0.877 & & & \\
\hline & SI4 & 0.909 & & & \\
\hline & SI5 & 0.780 & & & \\
\hline \multirow{4}{*}{$\begin{array}{l}\text { Facilitating Conditions } \\
\text { (FC) }\end{array}$} & FC1 & 0.862 & \multirow{4}{*}{0.880} & \multirow{4}{*}{0.918} & \multirow{4}{*}{0.736} \\
\hline & FC2 & 0.863 & & & \\
\hline & FC3 & 0.894 & & & \\
\hline & FC4 & 0.811 & & & \\
\hline \multirow{4}{*}{ Perceived Value (PV) } & PV1 & 0.855 & \multirow{4}{*}{0.926} & \multirow{4}{*}{0.948} & \multirow{4}{*}{0.819} \\
\hline & PV2 & 0.919 & & & \\
\hline & PV3 & 0.927 & & & \\
\hline & PV4 & 0.917 & & & \\
\hline
\end{tabular}




\subsection{Discriminant Validity}

Since issues of discriminant validity arise when the HTMT values are high, it cannot be ascertained when the HTMT value exceeds 0.90 . However, as seen in Table 4 , all the HTMT values were below 0.90 , thereby confirming the discriminant validity of the model.

Table 4. Heterotrait-monotrait Ratio (HTMT).

\begin{tabular}{ccccccc}
\hline HTMT & BI & EE & FC & PE & PV & SI \\
\hline BI & & & & & \\
\hline EE & 0.760 & & & & \\
\hline FC & 0.785 & 0.797 & & & \\
\hline PE & 0.777 & 0.803 & 0.720 & & & \\
\hline PV & 0.856 & 0.752 & 0.749 & 0.825 & & \\
\hline SI & 0.574 & 0.549 & 0.574 & 0.648 & 0.651 & \\
\hline
\end{tabular}

\subsection{Structural Model Analysis}

As seen in Figure 2 and Table 5, the results of the first hypothesis (H1) showed significant correlation between performance expectancy (PE) and behavioural intention ( $\beta=0.139, t=2.248, p<0.05)$. Therefore, $\mathrm{H} 1$ was supported. The results of the second hypothesis (H2) did not indicate a significant correlation between effort expectancy (EE) and BI ( $\beta=0.104, t=1.721, p>0.05)$. Similarly, the results of the third hypothesis (H3) also indicated that a significant correlation between social influence (SI) and BI did not exist ( $\beta=0.004, t=0.082, p>0.05)$. As such, both $\mathrm{H} 2$ and $\mathrm{H} 3$ were unsupported because the $\mathrm{t}$-values were $<1.96$ (the $Z$ value for $95 \%$ confidence) and the $p$-values were $>0.05$, indicating statistical insignificance. Thus, both these hypotheses were rejected. The results of the fourth hypothesis (H4) showed a positive correlation between facilitating conditions (FC) and BI $(\beta=0.220, \mathrm{t}=3.675, p<0.001)$. Therefore, $\mathrm{H} 4$ was supported and significant. Lastly, the results of the fifth hypothesis (H5) alluded to a significant correlation as perceived value $(\mathrm{PV})$ was found to positively influence BI $(\beta=0.469, \mathrm{t}=6.921, p<0.001)$. Therefore, H5 was supported.

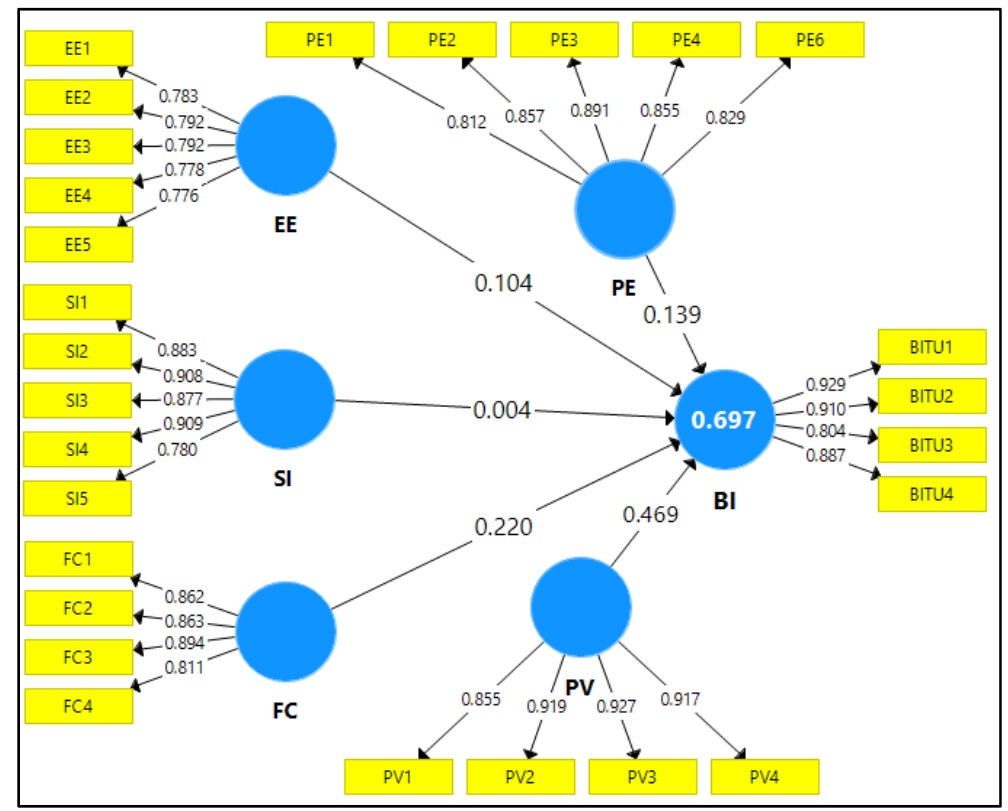

Figure 2. Path coefficients result. 
Table 5. Hypotheses testing result.

\begin{tabular}{ccccccc}
\hline Hypothesis & Path Links & VIF & $\begin{array}{c}\text { Path Coefficients } \\
(\boldsymbol{\beta})\end{array}$ & T-Values (t) & $\boldsymbol{p}$-Values $(\boldsymbol{p})$ & Supported? \\
\hline H1 & PE -> BI & 2.973 & 0.139 & 2.248 & $0.025^{*}$ & Yes \\
H2 & EE -> BI & 2.508 & 0.104 & 1.721 & 0.085 & No \\
H3 & SI -> BI & 1.708 & 0.004 & 0.082 & 0.934 & No \\
H4 & FC -> BI & 2.320 & 0.220 & 3.675 & $0.000^{* *}$ & Yes \\
H5 & PV -> BI & 2.935 & 0.469 & 6.921 & $0.000^{* *}$ & Yes \\
\hline
\end{tabular}

VIF = Variance Inflation Factor; $\mathrm{t} \geq 1.96 ;\left(^{* *}\right) p<0.01 ;\left(^{*}\right) p<0.05$.

As seen in Figure 2, the $\mathrm{R}^{2}$ was 0.697 . This meant that the independent factors in the model were able to estimate and describe $69.7 \%$ of the variance in the BI. The $\beta$ of all the factors was significant as it exceeded 0.10 for every factor except SI (0.004). Furthermore, the fifth hypothesis (H5) of PV on BI had the highest $\beta$. This indicated that PV played a major role in predicting and influencing BI.

After evaluating the proposed acceptance model for hypotheses, the structural model was then inspected for multicollinearity. This was determined by using SmartPLS to assess the variance inflation factor (VIF). VIF should, preferably, be $\leq 3.0$ [41]. As seen in Table 5, the VIF of each factor was either below or approximately 3.0. Therefore, there were no issues of multicollinearity between the predictor (independent) factors in the model.

\section{Discussion}

The purpose of this study was to identify the major factors affecting the acceptance and intention to utilise online learning platforms among the urban poor in the Klang Valley region of Malaysia using the model proposed in Figure 1. The unified theory of acceptance and use of technology (UTAUT) model was the fundamental hypothetical model utilised in this study in combination with the additional factor of perceived value (PV). This study provides quality insights into how well the urban poor have accepted online learning as well as their opinions of the platforms. The results of the SmartPLS software confirmed the internal consistency and reliability of the model. The findings of this study supported as well as highlighted the significance of three hypotheses; namely, performance expectancy or PE (H1), facilitating conditions or FC (H4), and perceived value or PV (H5) on the behavioural intention to use (BI) online learning platforms among the urban poor. Meanwhile, effort expectancy or EE (H2) and social influence or SI (H3) were not supported, which indicated that they negatively influenced the BI.

PV was found to be the most prominent factor as it is a perceptive trade-off between the potential advantages of online learning and a respondent's time and commitment to use it. As H5 (PV -> BI) was supported, it implied that respondents firmly believe that the value of online learning is not limited to monetary benefits, and educational benefits that are worth with the time and effort as well. This is corroborated by [29] and [42], who investigated the acceptance and implementation of Massive Open Online Courses (MOOCs). These studies also concluded that PV influenced BI, indicating that users are more willing to utilise MOOCs when they discovered that the benefits outweigh the cost of subscribing to MOOCs.

FC was the next important factor in this study. As H4 (FC -> BI) was supported, it indicated that respondents believe that technological infrastructure is available to assist their usage of any online learning platform. As all the respondents were urbanites, technological infrastructure played a crucial role in the acceptance of online learning in this demographic. Access to resources, such as excellent internet frequency ranges and sophisticated devices with which to access online learning platforms, should not be underestimated because it might be an influential factor in the acceptance of online learning by users. This is corroborated by [15], who verified that facilitating conditions can increase the convenience and enjoyment of performing mobile payments online.

PE (H1) was also discovered to be an imperative factor of BI. This signified that respondents believe that utilising online learning platforms will enable them to achieve good progression in their learning or careers that would help them to be promoted or 
increase their income. Similarly, studies by $[7,13]$ found that PE has an encouraging impact on a learners' intention to utilise online learning platforms throughout the learning process.

Conversely, as H2 (EE -> BI) was rejected, EE did not impact the BI to utilise online learning platforms among the urban poor. This indicated that respondents thought it would be hard to utilise online learning platforms. Therefore, if respondents believe that online learning platforms are unwieldy to use, they are less likely to use them. This is corroborated by [4], who discovered that, when users realised that some effort is required to utilise the eRezeki online platform, they were likely to use it. As such, they concluded that $\mathrm{EE}$ was not a vital element affecting BI.

Lastly, as H3 (SI -> BI) was rejected, SI did not impact the BI to utilise and accept online learning platforms among the urban poor. This indicated that respondents would not readily accept an online learning platform even if others believe that they should accept and use the platform. This is corroborated by multiple studies $[6,18,20,21,23]$. These studies concluded that a substantial causal correlation did not exist between SI and BI because learners have their own personal opinions on attending online classes or programmes despite the thoughts and opinions of their relatives, friends, or others.

\section{Conclusions}

This study included perceived value as an additional predictor in the unified theory of acceptance and use of technology (UTAUT) model to examine the acceptance and intention towards online learning platforms among the urban poor. Despite a lack of studies that utilise the UTAUT model in the context of online learning among the urban poor, it is hoped that this study will help authorities identify the factors affecting the acceptance of online learning among the urban poor. This study concluded that three factors in the proposed model, perceived value (PV), facilitating conditions (FC), and performance expectancy $(\mathrm{PE})$, significantly influence the acceptance and intention of the urban poor towards online learning. However, effort expectancy (EE) and social influence (SI) were insignificant factors as they did not directly impact the behavioural intention to use (BI) and accept online learning among the urban poor. It is safe to conclude that respondents believe that online learning will provide educational benefits that are worth the time and effort invested. Moreover, they trust that infrastructure, such as excellent internet frequency range and sophisticated devices, exists to support their access to online learning platforms. Apart from that, respondents also believe that accepting and employing these platforms will lead to good progress in learning or careers. This would, in turn, enable them to secure promotions and increase their income. However, this study utilised a cross-sectional method that failed to adequately evaluate the adoption of online learning among the urban poor communities. Therefore, future studies may consider conducting a longitudinal study while considering other possible factors collected via qualitative methods such as in-depth interviews, case study research, and focus groups.

Author Contributions: Conceptualisation, N.A., R.A., W.F.W.A. and Z.A.B.; methodology, N.A., R.A. and W.F.W.A.; software, N.A.; validation, N.A., W.F.W.A. and R.A.; formal analysis, N.A.; investigation, N.A.; data curation, N.A.; writing-original draft preparation, N.A.; writing-review and editing, N.A., R.A. and W.F.W.A.; supervision, W.F.W.A., R.A. and Z.A.B. All authors have read and agreed to the published version of the manuscript.

Funding: This research was funded by Yayasan Universiti Teknologi PETRONAS-Fundamental Research Grant (YUTP-FRG).

Institutional Review Board Statement: Not applicable.

Informed Consent Statement: Not applicable.

Data Availability Statement: The data shared in this article are obtainable on request from the corresponding author.

Conflicts of Interest: The authors declare no conflict of interest. 


\section{References}

1. Rozmi, A.N.A.; Bakar, M.I.A.; Abdul Hadi, A.R.; Nordin, A.I. Investigating the intentions to adopt ICT in Malaysian SMEs using the UTAUT model. Lect. Notes Comput. Sci. 2019, 11870 LNCS, 477-487.

2. Mayan, S.N.A.; Mohd Nor, R. The Resistance of the Urban Poor in Selangor, Malaysia to Get Out of the Shackles of Poverty. Int. J. Acad. Res. Bus. Soc. Sci. 2020, 10, 602-611.

3. Hadi, F.A.; Tha, G.P.; Zulkifli, N.; Ismail, Z.; Romli, N. The Involvement of B40 Entrepreneurs in E-Commerce: Experience from Malaysia. Int. J. Adv. Sci. Technol. 2020, 29, 265-271.

4. Hamid, N.A.; Haron, N.H.; Nik Abdullah, N.A.I.; Mohd Ali, M.; Abd Hamid, N.; Abdul Razak, N. The acceptance of the eRezeki digital platform in Kuala Selangor, Malaysia. Int. J. Innov. Creat. Chang. 2020, 13, 608-621.

5. Alsousi, A.; Ahmad Dahlan, A.R. The role of Malaysian UotF in the Pandemic and Digital Era: International Community Engagement for Humanizing Digital Entrepreneurship Education for the B40 Unemployed Graduate Palestinian Youths. Int. J. Comput. Sci. Inf. Technol. Res. 2021, 9, 53-64.

6. Department of Statistics Malaysia. Household Income and Basic Amenities Survey Report 2019; Department of Statistics Malaysia: Putrajaya, Malaysia, 2020; pp. 1-326.

7. Chen, P.; Hwang, G. An empirical examination of the effect of self- regulation and the Unified Theory of Acceptance and Use of Technology (UTAUT) factors on the online learning behavioural intention of college students. Asia Pac. J. Educ. 2019, 39, 79-95. [CrossRef]

8. Department of Statistics Malaysia. Salaries E Wages Survey Report 2020; Department of Statistics Malaysia: Putrajaya, Malaysia, 2021; pp. 1-6.

9. Lawrence, R.; Ching, L.F.; Abdullah, H. Strengths and Weaknesses of Education 4.0 in the Higher Education Institution. Int. J. Innov. Technol. Explor. Eng. 2019, 9, 511-519.

10. Shanmugam, K.; Zainal, N.K.; Gnanasekaren, C. Technology Foresight in the Virtual Learning Environment in Malaysia. J. Phys. Conf. Ser. 2019, 1228, 012068. [CrossRef]

11. Shee, D.Y.; Wang, Y.S. Multi-criteria evaluation of the web-based e-learning system: A methodology based on learner satisfaction and its applications. Comput. Educ. 2008, 50, 894-905. [CrossRef]

12. Perumal, I.; Abdullah, A.; Parthasarathy, R.; Jayabalan, N.; Subramaniam, M.; Perumal, G. A Paradigm Shift in Online Learning Practices among Primary School Teachers in Malaysia: Adaptive Learning System Framework. Int. J. Manag. 2020, 11, 410-418.

13. Chao, C. Factors Determining the Behavioral Intention to Use Mobile Learning: An Application and Extension of the UTAUT Model. Front. Psychol. 2019, 10, 1-14. [CrossRef] [PubMed]

14. Halili, S.H.; Razak, R.A. Information and Communications Technology Acceptance among Malaysian Adolescents in Urban Poverty. Turk. Online J. Educ. Technol. 2017, 16, 47-54.

15. Rozak, I.R.; Muna, A.; Musyaffi, A.M.; Siregar, N.F. Critical Factor of Mobile Payment Acceptance in Millenial Generation: Study on the UTAUT model. Int. Symp. Soc. Sci. Educ. Humanit. 2019, 306, 123-127.

16. Venkatesh, V.; Morris, M.G.; Davis, G.B.; Davis, F.D. User Acceptance Of Information Technology: Toward A Unified View. MIS Q. 2003, 27, 425-478. [CrossRef]

17. Kabra, G.; Ramesh, A.; Akhtar, P.; Kumar, M. Understanding behavioural intention to use information technology: Insights from humanitarian practitioners. Telemat. Inform. 2017, 34, 1250-1261. [CrossRef]

18. Aini, Q.; Rahardja, U.; Hariguna, T. The Antecedent of Perceived Value to Determine of Student Continuance Intention and Student Participate Adoption of ilearning. Procedia Comput. Sci. 2019, 161, 242-249. [CrossRef]

19. Yang, H.; Yu, U.; Zo, H.; Choi, M. User acceptance of wearable devices: An extended perspective of perceived value. Telemat. Inform. 2016, 33, 256-269. [CrossRef]

20. Yu, J.; Lee, H.; Ha, I.; Zo, H. User acceptance of media tablets: An empirical examination of perceived value. Telemat. Inform. 2017, 34, 206-223. [CrossRef]

21. Mandailina, V.; Saddam, S.; Ibrahim, M.; Syaharuddin, S. UTAUT: Analysis of Usage Level of Android Applications as Learning Media in Indonesian Educational Institutions. Int. J. Educ. Curric. Appl. 2019, 2, 16-23. [CrossRef]

22. Chauhan, S.; Jaiswal, M. Determinants of acceptance of ERP software training in business schools: Empirical investigation using UTAUT model. Int. J. Manag. Educ. 2016, 14, 248-262. [CrossRef]

23. Park, M.; Lee, J. Investigation of College Students' Intention to Accept Online Education Services: An Application of the UTAUT Model in Korea. J. Asian Financ. Econ. Bus. 2021, 8, 327-336.

24. Naranjo-Zolotov, M.; Oliveira, T.; Casteleyn, S. Citizens' intention to use and recommend e-participation: Drawing upon UTAUT and citizen empowerment. Inf. Technol. People. 2019, 32, 364-386. [CrossRef]

25. Abbad, M.M.M. Using the UTAUT model to understand students' usage of e-learning systems in developing countries. Educ. Inf. Technol. 2021, 1-20. [CrossRef]

26. Persada, S.F.; Miraja, B.A.; Nadlifatin, R. Understanding the Generation Z Behavior on D-Learning: A Unified Theory of Acceptance and Use of Technology (UTAUT) Approach. Int. J. Emerg. Technol. Learn. 2019, 14, 20-33. [CrossRef]

27. Padhi, N. Acceptance and Usability of OER in Indian Higher Education: An Investigation Using UTAUT Model. Open Prax. 2018, 10, 55-65. [CrossRef]

28. Hamdan, F.; Nordin, N.; Khalid, F. Understanding the Employees Acceptance on Online Training for Basic Managerial Finance. Creat. Educ. 2019, 10, 1305-1316. [CrossRef] 
29. Mulik, S.; Srivastava, M.; Yajnik, N. Extending UTAUT Model to Examine MOOC Adoption. NMIMS Manag. Rev. 2018, XXXVI, 26-44.

30. Zeithaml, V.A. Consumer Perceptions of Price, Quality and Value: A Means-End Model and Synthesis of Evidence. J. Mark. 1988, 52, 2-22. [CrossRef]

31. Raza, S.A.; Shah, N.; Ali, M. Acceptance of mobile banking in Islamic banks: Evidence from modified UTAUT model. J. Islam. Mark. 2020, 10, 357-376. [CrossRef]

32. Wang, Y.; Gu, J.; Wang, S.; Wang, J. Understanding consumers' willingness to use ride-sharing services: The roles of perceived value and perceived risk. Transp. Res. Part C 2019, 105, 504-519. [CrossRef]

33. Zeithaml, V.A.; Berry, L.L.; Parasuraman, A. The Behavioral Consequences of Service Quality. J. Mark. 1996, 60, 31-46. [CrossRef]

34. Kim, Y.H.; Kim, D.J.; Wachter, K. A study of mobile user engagement (MoEN): Engagement motivations, perceived value, satisfaction, and continued engagement intention. Decis. Support Syst. 2013, 56, 361-370. [CrossRef]

35. Shuib, L.; Yadegaridehkordi, E.; Ainin, S. Malaysian urban poor adoption of e-government applications and their satisfaction. Cogent Soc. Sci. 2019, 5, 1-18. [CrossRef]

36. Sabah, N.M. Exploring students' awareness and perceptions: Influencing factors and individual differences driving $\mathrm{m}$-learning adoption. Comput. Human Behav. 2016, 65, 522-533. [CrossRef]

37. Rahi, S. Research Design and Methods: A Systematic Review of Research Paradigms, Sampling Issues and Instruments Development. Int. J. Econ. Manag. Sci. 2017, 6, 1-5. [CrossRef]

38. Teymournejad, K.; Elghaei, R. Effect of Transformational Leadership on the Creativity of Employees: An Empirical Investigation. Eng. Technol. Appl. Sci. Res. 2017, 7, 1413-1419. [CrossRef]

39. Hair Jr, J.F.; Sarstedt, M.; Hopkins, L.; Kuppelwieser, V.G. Partial least squares structural equation modeling (PLS-SEM) An emerging tool in business research. Eur. Bus. Rev. 2014, 26, 106-121. [CrossRef]

40. Henseler, J.; Ringle, C.M.; Sarstedt, M. A new criterion for assessing discriminant validity in variance-based structural equation modeling. J. Acad. Mark. Sci. 2015, 43, 115-135. [CrossRef]

41. Hair, J.F.; Risher, J.J.; Ringle, C.M. When to use and how to report the results of PLS-SEM. Eur. Bus. Rev. 2019, 31, 2-24. [CrossRef]

42. Mohamed, E.; Nasef, M.; Mohd, N.M. Proposed Model of Students Acceptance of Massive Open Online Courses. Open Int. J. Inform. 2019, 7, 179-189. 